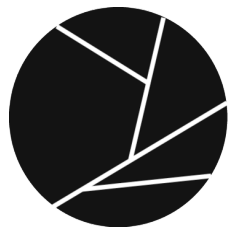

\title{
SOPHIA
}

PEER REVIEW JOURNAL

VISUAL SPACES OF CHANGE: DESIGNING INTERIORITY

SHELTER, SHAPE, PLACE, ATMOSPHERE

ISSN: 2183-8976 [PRINT] 2183-9468 [ONLINE]

Volume 5, Issue 1| Publication year: 2020

DOI 10.24840/2183-8976_2020-0005_0001_10

(c) SCOPIO EDITIONS

HOMEPAGE: $\underline{\text { HTTPS:/ /WWW.SOPHIAJOURNAL.NET }}$

\section{About the Book}

\section{Valerio Olgiati - Bas Princen . A Talk on Architecture in Photography}

\section{Images From Valerio Olgiati Personal}

Archive And Photographs By Bas Princen

\section{by Pedro Leão Neto}

As editor of scopio Editions it is a great honour to be writing this closing text about the present book which communicates our last Duelo/Dueto session of Architecture, Art and Image (AAI) series that had as invited authors Valerio Olgiati and Bas Princen. I will start by talking about the book as a privileged medium for Architecture, Art and Image and then go on focusing on this book in particular and its authors.

This conference series had from the start planned a publication for each session with the contribution of the invited speakers and the organization because we believe that the physical book, without prejudice towards the potential of digital publications, is still a tool of paramount importance for preserving and building knowledge, not just for students and academics, but also for all professionals and non-scholars.

The physical book somehow allows the understanding of what was discussed and debated in Duelo/Dueto sessions in a different manner, encouraging and giving the right time to each 
viewer for a deeper thinking. The reading of these sessions also means that these events of rich exchange of ideas and personal experience between significant authors coming from AAI universe are preserved for future studies. In this way, they can be shared with a larger audience, opening the mind of many to these events and encouraging critical thinking toward a vast horizon of issues related to AAl universe.

It is worth referring also that the specific potential of the physical book as a unique medium to communicate Architecture, Art and Image ${ }^{1}$ was explored in this publication, which adds to its uniqueness and makes it more an author's book than the customary conference or roundtable publication.

\footnotetext{
1 About the importance of building a sequence or visual narrative is to consider photography as a visual writing with its own grammar and syntax, as well as the potential that a sequence of images has to tell a story, or as Gerry Badget says, like the book of photography has a unique potential that challenges the photographer to build a visual discourse because forces the photographer to think about the reason that supports the chosen sequence of images see Neto, Pedro L. R. F. 2015. Art and documentary photography Architecture, City and Territory. In Cityzines, 56 - 76. ISBN: 978-989-97699-9-1. Porto, Portugal: scopio Editions; Imprint - Visual Narratives in books and Beyound by Gerry Badger, David Bate, Bettina Lockemann \& Michael Mack (http://www. tipitin.com/shop/imprint-visual-narratives-in-books-and-beyond-by-gerrybadger-david-bate- bettina-lockemann-michael-mack).
} 
It was possible to create a visual narrative where the sum is greater than the parts, which we believe has as a result an innovative reading and a more insightful understanding about the thoughts, work and artistic strategies of both authors. Thus, we believe that this book, the second of this series of four publications focused on each session, will foster a significant critical debate related to Architecture, Art and Image, as already happened with our first published book on this series.

The book's structure is twofold and the first part starts with the autonomous visual narratives of each author beginning with Valerio Olgiati and ending with Bas Princen. These image series should be understood not only as a visual "duelo / dueto", but also as two ways of understanding the world and specially the universes of architecture, photography and art. They are two free and open visual constructs from two creatives who are coming from the different but interrelated fields of architecture and photography. In fact, the long history of mutual interference between architecture and photography is acknowledged by many authors ${ }^{2}$, as well as their complex and ubiquitous relationship, which posits photography as a relevant exploratory, artistic and documentary research tool for architecture. As follows, the visual strategies of these authors forward two different critical insights on how to understand architecture and the territory bringing a new discourse over these disciplinary fields and expand the definition of photography.

The second part consists of the conference lectures and each author worked with editors and designers the layout they felt would better communicate the ideas of each in the conference. The challenge was to convey those ideas by combining text with image creating a complex interplay between them and allowing autonomy for both forms of expression and reading. The visual constructs and the text in first and second part of the book show us two extraordinary creatives and their approach to images within their work. Being one an architect and the other a photographer, it is interesting to note how they both place, in this second part, in between the images of their work, other images of travels, experiences, objects and other things which inform their work and, in this manner, create rich visual constructs that amplify its meaning and would be difficult to show otherwise.

2 Consider a number of publications looking at architecture through the lenses of the history of photography: Richard Pare, Photography and Architecture (Montreal and New York: Canadian Centre for Architecture and Callaway Editions, 1982); Cervin Robinson, Architecture Transformed: A History of the Photography of Buildings from 1839 to the Present (New York and Cambridge, MA: Architectural League of New York and MIT Press, 1987); Robert Elwall, Building with Light: the International History of Architectural Photography (London: Merrell, 2004).

Beatriz Colomina, "Introduction: On Architecture, Production and Reproduction," in Beatriz Colomina, ed., Architectureproduction (New York: Princeton Architectural Press, 1988), 15-16; see also Jean-Louis Cohen, "Introduction," in Le Corbusier, Toward an Architecture (Los Angeles: Getty Research Institute, 2007), 1-78.

Jean-Louis Cohen, “The Misfortunes of the Image: Melnikov in Paris, 1925 (on Architecture and Photography)," in Colomina, Architectureproduction, 101-121; see also Claire Zimmerman's comments on Adolf Loos in "Photographic Modern Architecture: Inside the 'New Deep,"' Journal of Architecture 9 (Autumn 2004): 331-54.

Hugh Campbell

David Campany 
Focusing on the visual constructs of first and second part of each author, starting with Valerio's series in the beginning, we see how he combines photographs of his work with other images that are an inspiration and inform his architecture, which may represent such diverse qualities as an atmosphere, or a composition, or an idea that in some way has been considered essential. It is important to note that these images, which inform about essential qualities, should not be understood as traditional historical or social referents, and can be linked to the idea of "Non-Referential" Architecture, the title of the book ideated by Valerio, and written by Markus Breitschmid, the internationally active architectural theoretician, historian, and author on architecture who teaches at Virginia Tech. In fact, as is explained in the book, Valerio's idea of non-referential architecture based on seven principles - Experience of Space, Oneness, Newness, Construction, Contradiction, Order, and Sensemaking - aims to be an architecture which is "form-generative" and "sense-making", creating meaning based on essential qualitative characteristics coming from inside the disciplinary field of architecture and not from outside i.e. historical, political or social fields. Be that as it may, this architecture is also a carrier of our era as is implied in this passage taken from the same book "Non-referential architecture is not an architecture that subsists as a referential vessel or as a symbol of something outside itself. Non-referential buildings are entities that are themselves meaningful and sense-making and, as such, no less the embodiment of society than buildings were in the past when they were the bearers of common social ideals." 3

All this can be inferred in the way Valerio interplays the different images in his visual constructs as, for instance, just to make a case in point, in the case of the plan of Mitla, the floor plan of a 2000 years old pre-Columbian Temple, that stands for the idea that how we read space is archaic and not so much a question of culture. In fact, as Valerio explains, those people never had contact with the Europeans, but the rooms of Mitla's plan undressed of any causal symbolism communicate, through geometry and location alone, which one of them is the most important room: the central and deepest room that is a destination and not a passage. This image informs the belief that an idea can be the DNA of the project as Valerio says and that buildings can evolve from this inner logic. Thus, he relates it in the first part with the image of his architecture - Villa Allem - that not only has this inner configurational rationale communicated by geometry and location alone, but also relates with Valerio's ideal of a perfect garden informed by the IndoPersian miniature image of three women in a white house, in the very centre of the world that was shown in the conference. 
Focusing now on Bas and the first part of the book, we see that his series starts with the photograph of Dendera, the brick wall installed image and then follows with several of his photographs of different places and situations, finishing with the "Ringroad Houston', 2005" also an installed photograph. All the photographs in this section are not references, but installed images of Bas' work that were used in spaces where exhibitions took place. It is interesting to recall here Beatrice von Bismark text "The art world as multiple: Lawrence Alloway and artists and photographs"4 when referring to Lawrence Alloway interpretations about photography and how he obliterated the differentiation "(...) between an object in a show and its documentary appearance in the publication." and he goes on saying "(...) As "variants" rather than "reproductions", the photographs were of equal status to him where they appeared in the exhibition or in the catalogue, was inconsequential: "Both the exhibited 'object'and the catalogue 'entry' are permutations made possible by the repeatability of the photographic process." In fact, the books can be taken as "alternative spaces" of exhibition and can also be itself thought as a medium of artistic expression exploring its specific form as an inspiration for creating an independent work of art, something we can see in many artists books. Coming back to the installed images of this first part we can say that the artistic rational and magic behind those images is a core quality of Bas' photographs and is well synthetized by Walter Benjamin's passage that Bas used in his text "Ringroad (Houston), 2005: the Construction of an Image" in Sophia journal Visual Spaces of Change: Unveiling the Publicness of Urban Space through photography and Image (2018). ${ }^{5}$ "Our eyes convey to us a surface image of things around us, and the mind processes the viewed objects into ideas and creates an inner world that we interpret in the most varied of ways"'.

\footnotetext{
4 Bradnock, Lucy et al. Lawrence Alloway: Critic and curator. Getty Research Institute, Los Angeles, 2015, 158, 159 ISBN 13:

9781606064429

5 Visual Spaces of Change: Unveiling the Publicness of Urban Space through Photography and Image. ISSN 2183-8976 [Print] 2183-9468 [Online]. Volume 4, Issue 1| Publication year: 20189. 37-46, DOI 10.24840/2183-8976_2019-0004_0001_07 6 August Sander, "Photography as a Universal Language", a lecture for WDR radio on Sunday 12 April 1931.
} 
In fact, as explained by Bas in many of his interviews and readings ${ }^{7}$ and also in this conference, he is interested in reinventing the world through photography or in other words to tell a story that is different from the referent, what is actually there being depicted. I believe this is the most important message of Bas and also the idea of exploring with photography the ambiguity between the natural and the man-made landscape, which we can see in many of his images as in Section (Petra) II, 2012 or Dendera's wall of bricks in which the artificial and the natural combine making us uncertain of what is natural or manmade and finally in the iconic image of the golden office block on the ringroad at the periphery of Houston, which as Bas explains has absorbed new references and new meanings and "It has become abstracted, losing any relation to the place and time of its making, and relating now instead to other images made before and after." 8

This is all quite significant and prepares the viewer for the interplay of images in the visual construct of his conference because in this second part it is now clear that Bas's references are on the left side and in a different scale of that of his photographs, which appear always on the right side. The combination of references and images allows the viewer to see how certain images informed his photographs as, for example, in the iteration between his image of the

'Future Olympic Park' in Beijing, where the storage of the sand to be used in the park with the green on their top looks both fictional and natural and is informed by an image of the early photographers from the American west. As Bas explains "it is the moment when industrial cities were starting to be made and they did a levelling of the hills to make Seattle by Asahel Curtis". Thus, not only is Bas' photography an autonomous critical territory, an instrument of thought and imagination, but also a means of culture interrelating the past and present and exploring the fictional. Maybe this is why the documentation process for Bas is never easy, it is not about just depicting what is out there, but in understanding the territory in a new way through photography.

7 Susana Ventura. 2012. "depict, depict, depicting". scopio International Photography Magazine 1 1/3 Aboveground: Territory:

98-129.; Bas Princen, edited by Vanessa Norwood.The Construction of an Image. Bedford Press, 2015. ISBN: 9781907414381 8 Visual Spaces of Change: Unveiling the Publicness of Urban Space through Photography and Image. ISSN 2183-8976 [Print] 2183-9468 [Online]. Volume 4, Issue 1| Publication year: 20189. 37, DOI 10.24840/2183-8976_2019-0004_0001_07 
Finally, it is worth mentioning that Bas is an artist and photographer who studied architecture at the Berlage Institute in Rotterdam, so this proximity to the universe of architecture and territory explains in same way that urban landscape became his artistic and study object. Having said that and having also explained how Bas' work is focused on urban landscape transformation, it is amazing how without being an architect his photography contributes for a new understanding about the world of architecture. As is explained by many authors as David Canpany, just to make a case in point, it is important for architecture the existence of autonomous and critical photography in contemporaneity. "If we accept that the experience of architecture may now be inseparable from the experience of its imagery, and that photography may now belong to the same networks of spectacle, comes clear that an independent and critical photography of architecture is as vital as it is jeopardered." 9

Then, it is also extraordinary to know how certain photographers and architects of contemporaneity are able to work with a high level of complicity and collaboration between them as pointed out by José Vassallo ${ }^{10}$ in his book Seamless-Digital Collage And Dirty Realism In Contemporary Architecture. In this book several examples are given that show how the autonomous and exploratory vantage point of the photographer participates actively in the conception process of architecture and speaking of Bas Princen, he calls the special relation he has with the collaboration of Kersten Geers and David van Severen.

We hope this physical book allow the understanding of what was discussed and debated in this Duelo/Dueto session with these two authors, Valerio Olgiati and Bas Princen, but maintaining an open perspective, to encourage and give the right time to each reader for a deeper thinking.

\footnotetext{
9 David Campany. "Architecture as Photography: document, publicity, commentary, art" written for the book of the exhibition

"Constructing Worlds: Photography and Architecture in the Modern Age" (Barbican Galley, 2014).

10 Jesús Vassallo. Seamless-Digital Collage And Dirty Realism In Contemporary Architecture. Park Books, December, 2016, ISBN 978-3-03860-019-0; See also the interview OFFICE Kersten Geers David Van Severen: Way of Seeing Things by by Heini Lehtinen In Living with Art \& Design, 2016 "In that perspective, we appreciate and really admire that a picture by Bas Princen is also a work on itself," he continues on a long-term collaborator, photographer Bas Princen. "It's never a documentary of architecture. He finds a space and takes a picture of it in his way with certain framing, and that's how he looks at the world. You could say the same about all the other works that are there. This kind of looking at the world in a certain way is also what architecture has in common. That certain way of looking is fundamental to us.", url: https://tlmagazine.com/ office-kgdvs-way-of-seeing-things/
} 


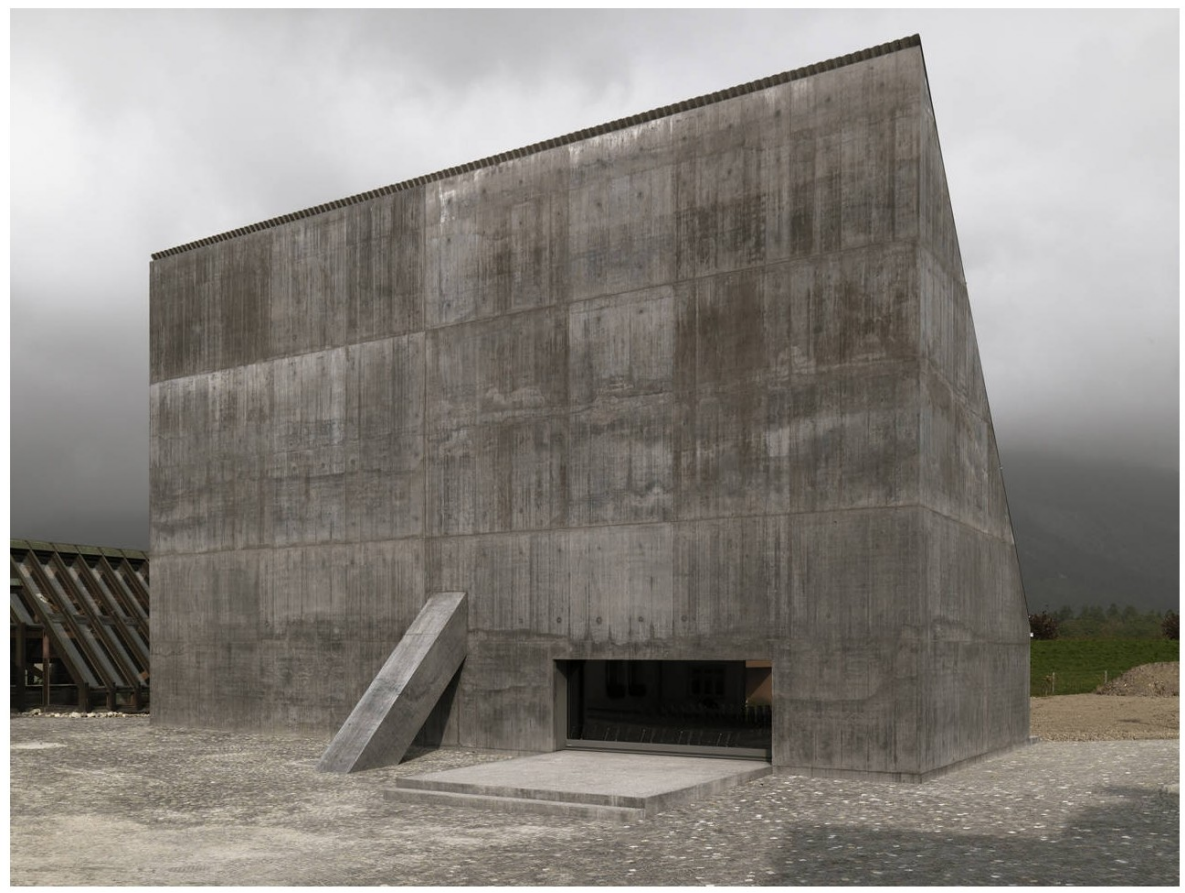

JAVIERMIGUEL VERME 


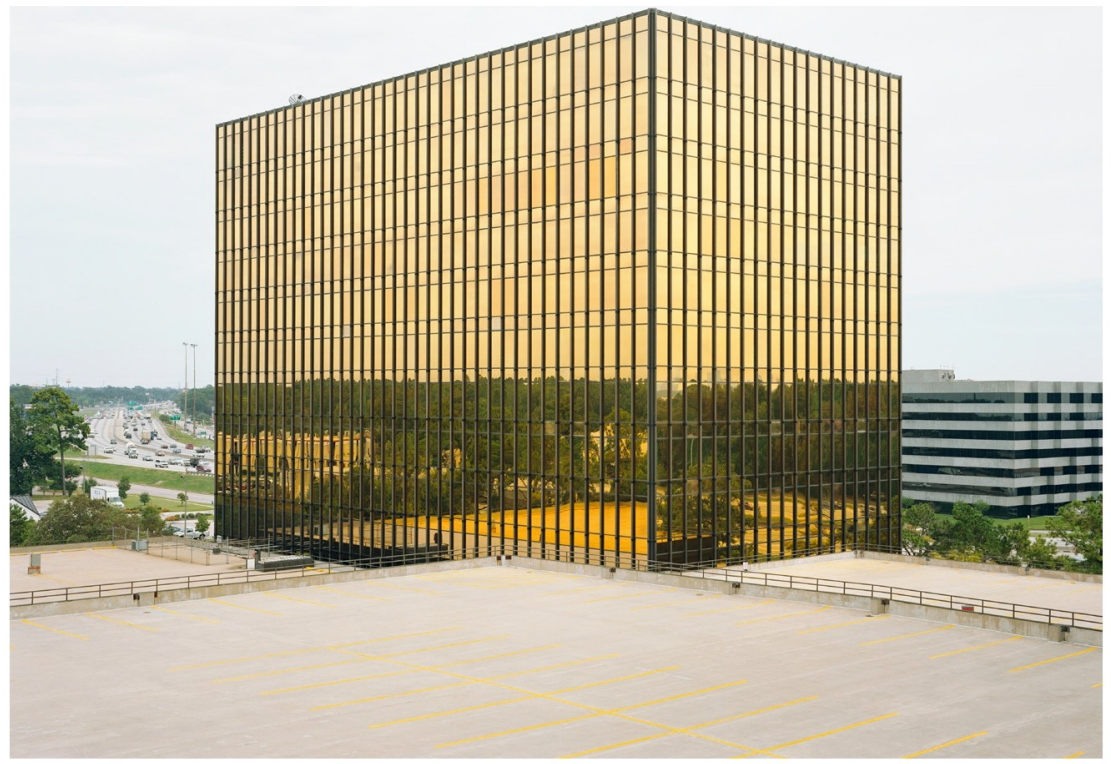

BAS PRINCEN

Ringroad (Houston), 2005 